\title{
Activation of rhodopsin kinase
}

\author{
Nina E. M. McCARTHY and Muhammad AKHTAR \\ Department of Biochemistry, University of Southampton, Bassett Crescent East, Southampton S016 7PX, Hants., U.K.
}

The present study confirms our original assertion that peptides corresponding to the $\mathrm{C}$-terminal sequence of rhodopsin are phosphorylated by rhodopsin kinase (RK), but only in the presence of photo-activated rhodopsin [Rho*, which is functionally equivalent to metarhodopsin II (Meta II)]. Under optimized conditions, the extent of peptide phosphorylation reached up to $60 \%$ that of Rho*. Rho* phosphorylation began to plateau within 15 min of the initiation of photolysis, whereas the peptide phosphorylation continued linearly for $>60 \mathrm{~min}$. This lack of co-ordination in the phosphorylation of the physio- logical (Rho*) and synthetic (peptide) substrates necessitated the present study, which showed that RK is activated for peptide phosphorylation not only by Meta II but also by Meta III, as well as by the phosphorylated derivatives of these species, but not by opsin. These results led to the conclusion that all the derivatives of opsin, which contain the Schiff base linkage with the all-trans-retinylidene moiety, retain the ability to activate RK.

Key words: metarhodopsin, opsin, retinyl, rhodopsin phosphorylation, Schiff base.

\section{INTRODUCTION}

The Ser/Thr phosphoryl transferase of retinal cell, rhodopsin kinase (RK) was the first member of a growing family of Gprotein-coupled receptor kinases (GRKs) to be discovered and is classified as GRK1. $\beta$-Adrenergic-receptor kinase-1 and -2 (GRK2 and 3) are two other well-studied members of the family, whereas three related kinases have been deduced from cDNA sequences [1]. Like other members of the family, RK phosphorylates only the stimulated form of the visual receptor, which is produced by the action of visible light on rhodopsin [2-4]. In other cases, the receptors become substrates for their cognate GRK, following agonist occupation (see [1] and references therein). The effect of light on the 11-cis-retinylidene chromophore of rhodopsin $\left(\lambda_{\max } \approx 498 \mathrm{~nm}\right)$ is complex, but at an ambient temperature and on a physiologically relevant time scale, it results in the production of a relatively long-lived intermediate metarhodopsin II (Meta II, $\lambda_{\max } 389 \mathrm{~nm}$ ) [5]. The latter is the activated species (symbolized as Rho*) that first triggers the visual cascade and is then inactivated by phosphorylation catalysed by RK [6]. The extraordinary specificity of RK which allows it to act on Rho*, but neither on the dark-adapted rhodopsin nor on the apoprotein opsin, was originally explained by suggesting that the site of phosphorylation, the C-terminal region of the receptor, becomes accessible only after conformational changes accompanying bleaching (see [7] and references therein). Using peptides corresponding to the C-terminal region of rhodopsin it was then discovered that these were phosphorylated by RK, but only in the presence of catalytic amounts of Rho* [8,9] or a C-terminal truncated form of Rho* [10]. This led to the proposal that RK is normally present in an inactive resting state and is activated following interaction with Rho*. Two broad mechanisms for the activation of RK were considered $[8,9]$ :

$$
\begin{aligned}
\mathrm{Rho}^{*}+\text { inactive } \mathrm{RK} & \rightarrow \mathrm{Rho}^{*} \cdot \text { inactive } \mathrm{RK} \\
& \rightarrow \mathrm{Rho}^{*} \cdot \text { active } \mathrm{RK}
\end{aligned}
$$

$$
\begin{aligned}
& \text { Rho* + inactive } \mathrm{RK} \rightarrow \mathrm{Rho}^{*} \cdot \text { inactive } \mathrm{RK} \rightarrow \mathrm{Rho}^{*} \cdot \text { active } \mathrm{RK} \\
& \leftrightarrow \mathrm{Rho}^{*}+\text { active } \mathrm{RK}
\end{aligned}
$$

Equation (1) assumes that the activated form of the enzyme is present only within a Rho* RK complex (see also $[1,10]$ ), whereas eqn (2) implies that RK may dissociate and independently exist as an activated entity.

Studies on the Rho*-dependent phosphorylation of synthetic peptide by RK have been extended to cover other aspects [11], e.g. the delineation of hierarchy of phosphorylation at different sites in Rho* [12]. Furthermore, it has been shown that GRK2 and GRK3 also phosphorylate synthetic peptides in the presence of the agonist-occupied form of their corresponding receptors $[13,14]$. Despite these sporadic observations, the activation hypothesis has been viewed with scepticism [15]. Here we establish optimal conditions for the Rho*-dependent phosphorylation of synthetic peptides and for the characterization of the form(s) of Rho* able to activate the kinase.

\section{MATERIALS AND METHODS}

\section{Materials}

$\left[\gamma-{ }^{32} \mathrm{P}\right]$ ATP was obtained from Amersham, OptiPhase 'Hisafe' 3 liquid-scintillation-cocktail from Fison's Chemicals and AG1X2 (acetate form) anion-exchange media was from Bio-Rad (Richmond, CA, U.S.A.); all other chemicals were purchased either from Sigma or Aldrich.

The buffers used in this work were as follows: buffer $\mathrm{A}$ : $70 \mathrm{mM}$ phosphate $/ 2 \mathrm{mM} \mathrm{MgCl}_{2} / 0.1 \mathrm{mM}$ EDTA/ $2 \mathrm{mM}$ dithiothreitol $/ 1 \mathrm{mM}$ benzamidine $/ 0.2 \mathrm{mM}$ phenylmethanesulphonyl fluoride ( $\mathrm{pH} 7.4)$; buffer B: as in buffer A except that $70 \mathrm{mM}$ phosphate was replaced by $20 \mathrm{mM}$ 1,3-bis[tris(hydroxymethyl)methylamino]propane (Bis-Tris propane); buffer $\mathrm{C}: 100 \mathrm{mM}$ Tris $/ 2 \mathrm{mM} \mathrm{MgCl}_{2} / 1 \mathrm{mM}$ EDTA/1 mM dithiothreitol $(\mathrm{pH} 7.4$ at $37^{\circ} \mathrm{C}$ ).

Abbreviations used: RK, rhodopsin kinase (GRK1); GRK, G-protein-coupled receptor kinase; GRK2 and GRK3, $\beta$-adrenergic-receptor kinases-1 and -2; 11-mer Rho, ${ }^{338}$ SKTETSQVAPA ${ }^{348}$, residues 338-348 of the C-terminal of bovine rhodopsin; Meta II, III, metarhodopsin II, III; Rho*, bleached rhodopsin (considered to be equivalent to Meta II); ROS, rod outer segment; TFA, trifluoroacetic acid.

1 To whom correspondence should be addressed (e-mail M.Akhtar@soton.ac.uk). 


\section{Methods}

Synthesis of 11-mer Rho ${ }^{338}$ SKTETSQVAPA ${ }^{348}$, residues $338-348$ of the C-terminal of bovine rhodopsin) peptide (hereafter referred to as the peptide substrate)

The 11-mer Rho sequence, corresponding to the amino-acid sequence of residues 338-348 of the C-terminal tail of bovine rhodopsin and its phosphorylated derivative were synthesized as stated previously [11].

A general procedure for the study of the phosphorylation of Rho* and the peptide substrate by RK

Ovine rod outer segments (ROS), urea-washed ROS and RK were prepared and processed as described previously, except that both ROS and urea-washed ROS were finally taken up into buffer B (see [16] and references therein). Generally, the RK used had an activity of $7-18$ units $/ \mathrm{ml}$ ( 1 unit $\approx 2 \mu \mathrm{g}$ of $\mathrm{RK}$ protein [17]). One unit of RK catalyses the incorporation of $1 \mathrm{nmol}$ of ${ }^{32} \mathrm{P} / \mathrm{min}$ from $\left[\gamma^{32} \mathrm{P}\right] \mathrm{ATP}$ in Rho*, isolated and analysed as phospho-opsin at $37^{\circ} \mathrm{C}$ in the assay system described below. Typically, experiments were performed on samples of 300-450 $\mu 1$.

A sample in a final volume of $450 \mu 1$ consisted of $45 \mu 1$ of ureawashed ROS (4.5 nmol), $45 \mu 1$ of $\left[\gamma^{-32} \mathrm{P}\right] \mathrm{ATP}(2.8 \mathrm{mM}$ in the final solution; $2.5 \times 10^{5}$ c.p.m. $/ \mathrm{nmol}$ ), $315 \mu \mathrm{l}$ of RK (2.9 units $(0.1 \mathrm{nmol})$ and $45 \mu \mathrm{l}$ of peptide substrate in buffer A ( $2 \mathrm{mM}$ final concentration). Samples were vortex-mixed, sonicated and incubated in the dark for $10 \mathrm{~min}$ at $37^{\circ} \mathrm{C}$ (unless stated otherwise) and then exposed to continuous light for $60 \mathrm{~min}$ (unless stated otherwise), with identical foil-wrapped tubes serving as dark controls. During the course of the reaction samples were occasionally agitated and vortexed to prevent sedimentation of ROS membranes. Aliquots of $10 \mu 1$ were removed at various time points and precipitated with $1 \mathrm{ml}$ of $20 \%$ (w/v) aq. trichloroacetic acid. The pellet was centrifuged at $10000 \mathrm{~g}$ for $3 \mathrm{~min}$ and washed twice with $1 \mathrm{ml}$ of $10 \%(\mathrm{w} / \mathrm{v})$ aq. trichloroacetic acid containing $10 \mathrm{mM}$ phosphate $(10000 \mathrm{~g}$ for $3 \mathrm{~min})$. The pellet was solubilized in $200 \mu \mathrm{l}$ of formic acid and, after mixing with $1.5 \mathrm{ml}$ of OptiPhase 'Hisafe' 3, subjected to scintillation counting. The accompanying phosphorylation of peptide substrate was monitored by quenching $50-80 \mu \mathrm{l}$ of the incubation mixture in $300 \mu 1$ of $7 \%$ (v/v) aq. acetic acid. Samples were centrifuged (10000 $g$ for $3 \mathrm{~min}$ ) and the supernatant $(300 \mu \mathrm{l})$ passed down an AG-1X anion-exchange column $(1.5 \mathrm{ml})$ equilibrated with $7 \%$ $(\mathrm{v} / \mathrm{v})$ aq. acetic acid to remove $\left[\gamma^{3}{ }^{32} \mathrm{P}\right] \mathrm{ATP}$. For each sample, $6 \mathrm{ml}$ of eluant was collected and lyophilized before being taken up into $800 \mu \mathrm{l}$ of $0.1 \%(\mathrm{v} / \mathrm{v})$ trifluoroacetic acid (TFA) in AnalaR water and the solution centrifuged $(10000 \mathrm{~g}$ for $3 \mathrm{~min})$ to remove contaminating $\mathrm{AG}-1 \mathrm{X}$ resin. A $300 \mu$ l aliquot was subjected to analytical reverse-phase-HPLC $\left(\mathrm{C}_{18}\right.$ column $)$ with a linear gradient of $0.1 \%$ aq. TFA and acetonitrile containing $0.1 \%$ TFA. Fractions of $1 \mathrm{ml}$ were collected and $500 \mu \mathrm{l}$ aliquots subjected to scintillation counting. Generally, $>95 \%$ of the counts loaded on to the column eluted at $37 \%$ acetonitrile, which corresponds to the position of the authentic 11-mer Rho phosphopeptide.

Phosphorylation of peptide substrate in a detergent-solubilized system was performed identically with that stated above with urea-washed ROS membranes replaced by urea-washed rhodopsin solubilized in $2 \%(\mathrm{w} / \mathrm{v})$ dodecyl maltoside in buffer B (for preparation refer to [16]). Furthermore, the peptide work-up was identical with that for the membrane system mentioned above.
RK-catalysed phosphorylation with addition of $\left[\gamma^{-}{ }^{32} P\right] A T P$, at 0 and 30 min after the initiation of illumination

This was performed using the general protocol described above except that it was conducted at $20{ }^{\circ} \mathrm{C}$ for $120 \mathrm{~min} .\left[\gamma^{3}{ }^{32} \mathrm{P}\right] \mathrm{ATP}$ was added to one sample at zero time, whereas another was supplemented with $\left[\gamma^{32} \mathrm{P}\right]$ ATP $30 \mathrm{~min}$ after the initiation of illumination.

\section{Preparation of phosphorylated opsin}

A mixture containing $150 \mu \mathrm{l}$ of urea-washed ROS (6-9 nmol), $131 \mu 1$ of $\left[\gamma^{32} \mathrm{P}\right] \mathrm{ATP}$ (final concentration $2.5-3.5 \mathrm{mM}$ with a specific activity of $2 \times 10^{3}-4 \times 10^{3}$ c.p.m./nmol) and $1200 \mu \mathrm{l}$ of RK (12-20 units) was thoroughly vortexed and sonicated in an ice-water bath $(3 \mathrm{~min})$ before incubation in the dark at $37^{\circ} \mathrm{C}$ for $10 \mathrm{~min}$. The sample was then exposed to continuous light for $30 \mathrm{~min}$, with occasional agitation and vortexing to prevent sedimentation of ROS membranes. The reaction was stopped by terminating illumination and, in order to remove excess $\left[\gamma-{ }^{32} \mathrm{P}\right]$ ATP from the phosphorylated opsin sample, was washed twice with $5 \mathrm{ml}$ of buffer A and ultracentrifuged (240000 $g$ for $10 \mathrm{~min}$ ). The pellet was taken up into $50 \mu \mathrm{l}$ of buffer A to give a final volume of $100 \mu 1$ with a final concentration of approx. $300 \mu \mathrm{M}$. To determine the incorporation of ${ }^{32} \mathrm{P}$ into opsin, $10 \mu \mathrm{l}$ aliquots were removed during the course of the reaction and subjected to trichloroacetic acid precipitation as discussed above. ${ }^{32} \mathrm{P}$ incorporation of $\geqslant 5 \mathrm{nmol}$ of ${ }^{32} \mathrm{P}$ per nmol opsin was used for the generation of phosphorylated isorhodopsin as will be shown below. In order to generate non-phosphorylated opsin, an Eppendorf tube identical with that above, but with $1331 \mu \mathrm{l}$ of buffer A replacing $\left[\gamma_{-}{ }^{32} \mathrm{P}\right] \mathrm{ATP}$ and RK, was set up and processed in parallel with the above sample.

\section{Regeneration with 9-cis-retinal to form phosphorylated isorhodopsin}

A solution of 9-cis-retinal was prepared by the addition of $20 \mu \mathrm{l}$ of Tween $80 \mathrm{in}$ acetone $(250 \mathrm{mg} / \mathrm{ml})$ to $500 \mu \mathrm{g}$ of 9-cis-retinal in an Eppendorf tube. The acetone was evaporated using a stream of nitrogen gas, $100 \mu \mathrm{l}$ of AnalaR water was added and the concentration of aqueous 9-cis-retinal $\left(\lambda_{\max } 387 \mathrm{~nm}\right)$ was determined spectroscopically.

Approximately $2 \mathrm{M}$ equivalents of aq. 9-cis-retinal was added to the phospho-opsin as discussed above and the sample incubated in the dark at room temperature for $1 \mathrm{~h}$. Regeneration to give phosphorylated isorhodopsin was confirmed by monitoring the absorbance at $490 \mathrm{~nm}$ ( $\lambda_{\max }$ of isorhodopsin) before, during and after incubation with 9 -cis-retinal by the removal of $5 \mu 1$ aliquots into $195 \mu \mathrm{l}$ of $3 \%$ (w/v) $N, N$-dimethyl dodecylamine in buffer B. In order to confirm the absence of phosphatase activity during regeneration, the ${ }^{32} \mathrm{P}$ content of phospho-isorhodopsin was monitored by the removal of $5 \mu 1$ aliquots for trichloroacetic acid precipitation as discussed above.

Phosphorylation of the peptide substrate in the presence of isorhodopsin or phosphorylated isorhodopsin

A $350 \mu 1$ sample consisted of $245 \mu 1$ of RK (2.3 units), $35 \mu 1$ of [ $\gamma-$ $\left.{ }^{32} \mathrm{P}\right]$ ATP (final concentration $2.8 \mathrm{mM} ; 3.4 \times 10^{5}$ c.p.m./nmol), $35 \mu$ of peptide substrate in buffer A (final concentration $2 \mathrm{mM}$ ) and $35 \mu \mathrm{l}$ of either phosphorylated isorhodopsin $(5 \mathrm{nmol}$ phosphate per nmol opsin) or isorhodopsin (both $10.5 \mathrm{nmol}$ ). The experiment was conducted as discussed in the General Procedure section above. 


\section{Rho* and peptide phosphorylation in the presence of $\mathrm{NH}_{2} \mathrm{OH}$}

A $350 \mu 1$ sample consisted of $245 \mu 1$ of RK (2.5 units), $35 \mu 1$ of $\left[\gamma_{-}{ }^{32} \mathrm{P}\right]$ ATP (final concentration $3 \mathrm{mM}: 8.6 \times 10^{4}$ c.p.m. $/ \mathrm{nmol}$ ), $35 \mu \mathrm{l}$ of urea-washed ROS (6.2 nmol), $17.5 \mu \mathrm{l}$ of peptide substrate in buffer A (final concentration $2 \mathrm{mM}$ ) and $17.5 \mu \mathrm{l}$ of aq. $\mathrm{NH}_{2} \mathrm{OH}$ (final concentration $0.25 \mathrm{mM}$ ). An identical control was set up which contained buffer $\mathrm{A}$ in place of $\mathrm{NH}_{2} \mathrm{OH}$ and identical foilwrapped tubes served as dark controls. All samples were vortexmixed, sonicated and incubated in the dark for $10 \mathrm{~min}$ at $20{ }^{\circ} \mathrm{C}$ before the introduction of continuous light. The incubation was conducted for $120 \mathrm{~min}$ at $20^{\circ} \mathrm{C}$ and the other details are as described under the General Procedure section above.

Schiff base cleavage in ovine ROS membranes in the presence of $\mathrm{NH}_{2} \mathrm{OH}$

The Schiff base cleavage under the above conditions was studied in an independent experiment as follows: $1 \mathrm{ml}$ of ROS membranes $(12.5 \mathrm{nmol})$ in buffer $\mathrm{C}\left(\mathrm{pH} 8.0\right.$ at $20^{\circ} \mathrm{C}$ containing a final concentration of $0.25 \mathrm{mM} \mathrm{NH} \mathrm{m}_{2} \mathrm{OH}$ ) was incubated at $20^{\circ} \mathrm{C}$ for $10 \mathrm{~min}$ in the dark with occasional agitation and vortexing to prevent sedimentation of ROS membranes. The sample was exposed to continuous light and $80 \mu \mathrm{l}$ aliquots were removed at various times and added into $120 \mu \mathrm{l}$ of an acid/detergent solution [3\% (w/v) $N, N$-dimethyl-dodecylamine- $N$-oxide in $0.2 \mathrm{M}$ aq. $\mathrm{HCl}$; $\mathrm{pH} 2-3]$. The Schiff base present was determined using the ratio of absorption at $440 \mathrm{~nm}$ [ $N$-retinylidene opsin (NRO) which is formed from various Schiff base linked derivatives of rhodopsin under acid-denaturing conditions] and $380 \mathrm{~nm}$ (due to all-trans-retinal oxime; although the $\lambda_{\max }$ for this species is $365 \mathrm{~nm}$ under these conditions, this wavelength was selected for convenience). A standard curve correlating the percentage Schiff base cleavage in the presence of $\mathrm{NH}_{2} \mathrm{OH}$ with the $A_{440} / A_{380}$ ratio was constructed using a modification of the method of DePont et al. [18] as follows : $500 \mu$ l of ovine ROS membranes $(62.5 \mathrm{nmol})$ was added to $4.5 \mathrm{ml}$ of $3 \%(\mathrm{w} / \mathrm{v}) \mathrm{N}, \mathrm{N}$-dimethyl-dodecylamine$\mathrm{N}$-oxide in buffer $\mathrm{C}\left(\mathrm{pH} 8.0\right.$ at $\left.20^{\circ} \mathrm{C}\right)$ containing $\mathrm{NH}_{2} \mathrm{OH}$ to give a final concentration of $12.5 \mu \mathrm{M}$ rhodopsin and $10 \mathrm{mM}$ $\mathrm{NH}_{2} \mathrm{OH}$. Two Eppendorf tubes containing $1 \mathrm{ml}$ of this solution were incubated in the dark at $20^{\circ} \mathrm{C}$ for $10 \mathrm{~min}$. One of the tubes was then wrapped in tin foil and the other exposed to continuous light for $6 \mathrm{~min}$. Unbleached and bleached samples were assumed to contain $100 \%$ and $0 \%$ Schiff base, respectively. Both samples were placed on ice immediately and processed in the dark. To Eppendorf tubes on ice, containing $120 \mu \mathrm{l}$ of $0.2 \mathrm{M}$ $\mathrm{HCl}$, a total volume of $80 \mu \mathrm{l}$ comprising a mixture of unbleached and bleached samples of rhodopsin containing the following compositions were added: $80,70,60,50,40,30,20,10$ and $0 \mu 1$ of the unbleached solution and the remaining volume made up with Rho*. The $A_{440} / A_{380}$ was plotted versus the calculated percentage Schiff base. The spectroscopic blank was identical with the experimental cell except that the $80 \mu 1$ sample was replaced by $80 \mu \mathrm{l}$ of $3 \%(\mathrm{w} / \mathrm{v}) \mathrm{N}, \mathrm{N}$-dimethyl-dodecylamine- $N$ oxide in buffer $\mathrm{C}\left(\mathrm{pH} 8.0\right.$ at $\left.20^{\circ} \mathrm{C}\right)$.

\section{Phosphorylation of the peptide substrate in the presence of opsin}

The experiment was conducted as in the General Procedure above except that in one experiment, urea-washed ROS was replaced by opsin (prepared as stated below).

\section{Preparation of opsin}

Urea-washed ROS $(5.12 \mathrm{mg})$ in buffer B containing $\mathrm{NH}_{2} \mathrm{OH}$ (10 $\mathrm{mM}$ final concentration) was exposed to continuous light
(30 min at $20^{\circ} \mathrm{C}$ ) and immediately centrifuged $(10000 \mathrm{~g}$ for 3 min at $\left.4{ }^{\circ} \mathrm{C}\right)$. The resultant pellet was washed in buffer $\mathrm{B}(3 \mathrm{ml})$ by repeated centrifugations (three times as above) in order to remove excess $\mathrm{NH}_{2} \mathrm{OH}$. Opsin was characterized using Schiff base content (as stated above except buffer $\mathrm{C}$ did not contain $\mathrm{NH}_{2} \mathrm{OH}$ ) and opsin concentration (using $A_{280}$ and $\epsilon=$ $64000 \mathrm{M}^{-1} \cdot \mathrm{cm}^{-1}$ ) [19], where $0 \%$ of the initial Schiff base was found to exist and a recovery of $79 \%$ of the starting amount of protein obtained.

\section{RESULTS}

\section{The extent and time course of peptide substrate phosphorylation by $\mathrm{RK}$}

In order to demonstrate the Rho*-dependent phosphorylation of synthetic peptide substrates by RK beyond any reasonable doubt, it was important to establish conditions under which the differences between the phosphorylation levels in the dark and light were maximized. Therefore several improvements were introduced which included the use of larger amounts of the enzyme, higher specific activity of $\left[\gamma_{-}{ }^{32} \mathrm{P}\right]$ ATP and exhaustive purification of the phosphorylated peptide so that it was completely free of any contaminating radioactivity. Figure 1 describes two types of experiments in which the phosphorylation of protein and peptide substrate was studied using Rho* either in ROS membranes or solubilized in dodecyl maltoside. In both systems, the phosphorylation levels of Rho* were identical, leading to the incorporation of $4 \mathrm{~mol}$ of phosphate per mol of receptor protein, and the bulk of the phosphorylation was complete within $15 \mathrm{~min}$ of the initiation of photolysis. In these and other experiments, the molar ratio of Rho/RK was $4.5: 0.1$ which, together with the stoichiometry of phosphate incorporation allows the estimation that during the overall conversion, each molecule of RK had turned over approx. 180 times. The Rho* phosphorylation was

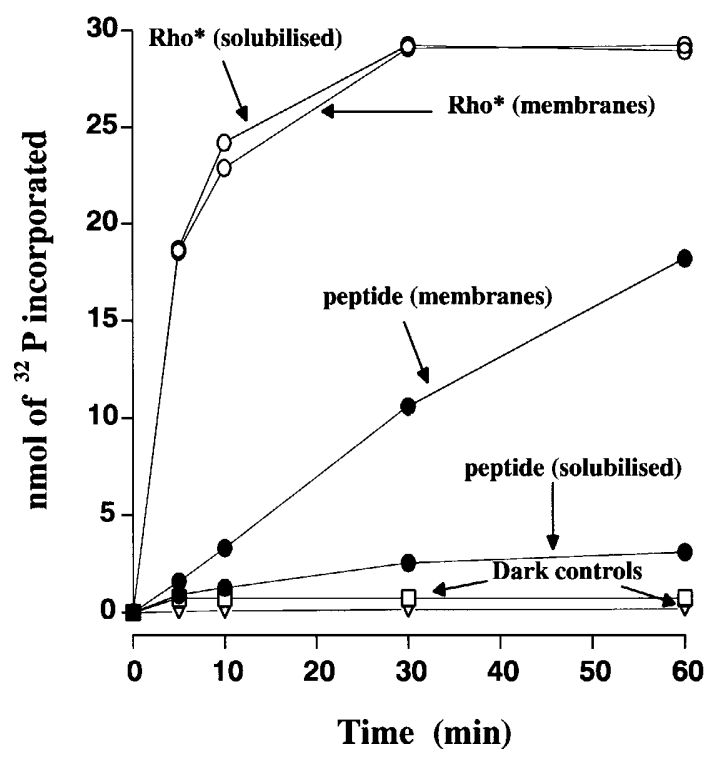

Figure 1 Comparison of the light-dependent phosphorylation of Rho* and peptide substrate by RK using a detergent-solubilized or membrane system

The final ${ }^{32} \mathrm{P}$ incorporation into Rho* in both the detergent-solubilized and the membrane system (two upper curves) gave the same final incorporation of $4 \mathrm{nmol}$ phosphate per nmol receptor protein. The dark control for Rho* $(\square)$ and peptide substrate $(\nabla)$ incorporated ${ }^{32} \mathrm{P}$ less than 5 and $1 \%$, respectively compared with the experiment conducted in the light. A typical result of four independently performed experiments is shown. 
quantified using the trichloroacetic acid precipitation method and showed that the control experiments, performed in the dark, incorporated less than $5 \%$ of the ${ }^{32} \mathrm{P}$ found in light. Since the Rho* phosphorylation is not a contentious issue, it was not deemed necessary to reduce further the background radioactivity by studying the incorporation specifically into receptor protein following separation by electrophoresis.

For peptide phosphorylation, the samples were rigorously purified by ion-exchange chromatography followed by reversephase HPLC and the time course of ${ }^{32} \mathrm{P}$ incorporation studied for up to $1 \mathrm{~h}$. At that time, in the membrane system, the level of peptide phosphorylation had reached approx. $60 \%$ of the Rho* phosphorylation with less than $1 \%$ incorporation of ${ }^{32} \mathrm{P}$ in the control experiments performed in the dark. In the soluble system, however, the peptide phosphorylation was reduced in a timedependent manner, being 66,38 and $25 \%$ of the membrane system at 5, 10 and $30 \mathrm{~min}$, respectively. Several factors may contribute to the impairment of peptide phosphorylation; one is the relatively facile hydrolysis of the Schiff base, in the detergentsolubilized system, producing opsin, which is not an activator of RK. It has been shown that the hydrolysis of the Schiff base linkage of Meta II is several times faster in dodecyl maltoside solution than in ROS membranes [20].

\section{Meta II, Meta III and their phosphorylated forms activate RK for peptide substrate phosphorylation}

In the membrane system, it was surprising that the phosphorylation of the peptide substrate continued linearly for more than $30 \mathrm{~min}$, and longer in experiments not shown, after the phosphorylation of Rho* had been completed. This led to the investigation of the types of photointermediates of rhodopsin that are capable of activating RK for peptide substrate phosphorylation. Hence, we took advantage of our recent work [16] in which it was shown that the decay of Meta II into Meta III could be smoothly and accurately monitored spectroscopically at $20{ }^{\circ} \mathrm{C}$ in ovine membranes when the $t_{1 / 2}$ for both the decay of Meta II and the formation of Meta III was approx. $3.2 \mathrm{~min}$, and at $30 \mathrm{~min}$ post-photolysis the equilibrium between Meta II and Meta III had been fully established. Phosphorylation experiments were now performed at $20^{\circ} \mathrm{C}$ closely mimicking the spectroscopic conditions. Samples containing ovine ROS membranes and RK were bleached and one set supplemented with $\left[\gamma^{-}{ }^{32} \mathrm{P}\right]$ ATP immediately and the other after $30 \mathrm{~min}$. Figure 2 shows that the time-course profiles for the incorporation of ${ }^{32} \mathrm{P}$ into Rho* as well as the peptide substrate were parallel for both the sets. These experiments highlight that Meta III is as good a kinase substrate as Meta II and, more importantly, both Meta II and Meta III are equally effective in activating RK for catalysing the phosphorylation of a peptide substrate.

Next, the ability of the phosphorylated form of Meta II and Meta III to activate RK for catalysing peptide substrate phosphorylation was investigated. Samples of opsin or phosphorylated opsin (containing $5 \mathrm{nmol}$ phosphate/nmol opsin) were prepared in parallel incubations and each regenerated with 9-cis-retinal to yield isorhodopsin and phosphorylated isorhodopsin, respectively. The choice of 9-cis-retinal was based on its commercial availability in a crystalline form, which ensured that identical amounts of the chromophore were used in the two regeneration experiments. Two sets of incubations were performed containing the peptide substrate, $\left[\gamma_{-}{ }^{32} \mathrm{P}\right] \mathrm{ATP}, \mathrm{RK}$ and either isorhodopsin or phosphorylated isorhodopsin. The photolysis of these should produce the 'same' Meta II and phosphorylated Meta II, which would be formed from the corresponding 11-cis-retinal-based proteins. In the incubation

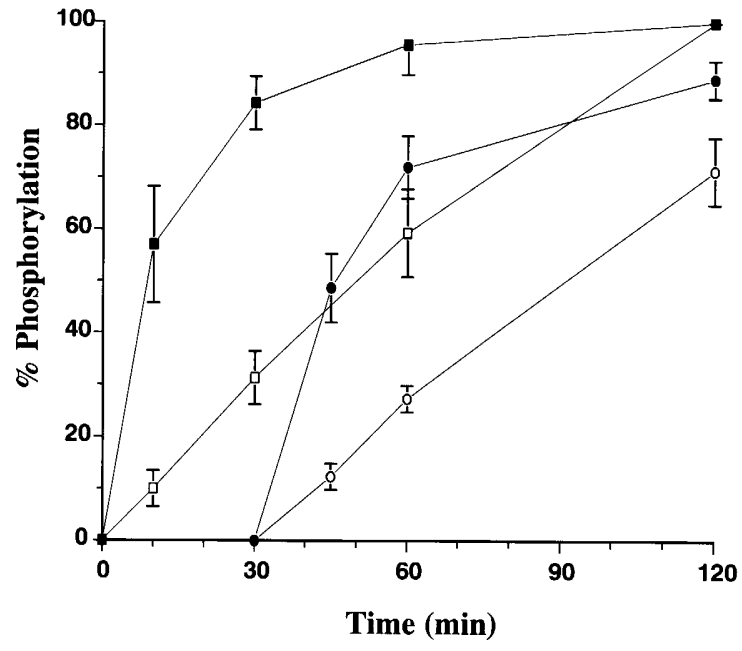

Figure 2 Time-course profile of RK-catalysed phosphorylation at $20{ }^{\circ} \mathrm{C}$ in incubation supplemented with $\left[\gamma-{ }^{32} P\right] A T P$ at $\mathbf{O}$ and 30 min following the initiation of illumination

The results of three independent experiments \pm S.D. are shown. The maximum incorporation of ${ }^{32} \mathrm{P}$ into Rho* and into the peptide substrate in the incubation supplemented with ATP at zero time is taken as $100 \%$. In a typical experiment, 42.8 and $18 \mathrm{nmol}$ of ${ }^{32} \mathrm{P}$ were incorporated into Rho* and the peptide substrate, respectively. $\mathbf{\square}, \mathbf{O}$, Phosphorylation of Rho*; $\square$, $\bigcirc$, peptide.

containing isorhodopsin, the expected incorporation of phosphate into the protein (at $60 \mathrm{~min}, 3.8 \mathrm{nmol}$ phosphate per nmol receptor protein with dark controls containing less than $2 \%$ of that incorporated in the light experiment; Figure 3) as well as the peptide substrate was achieved. More significantly, however, the time course and the extent of peptide phosphorylation were the same whether the activation of RK was triggered by bleached isorhodopsin or bleached phosphorylated isorhodopsin. It is to be noted that in the experiment containing phosphorylated isorhodopsin, a further incorporation of $1.2 \mathrm{nmol}$ phosphate per nmol receptor protein occurred. If, for the sake of argument, it is assumed that the latter incorporation involved the phosphorylation of a completely unphosphorylated population then the upper limit of this unphosphorylated isorhodopsin in the original sample will be less than $20 \%$ and not sufficient to activate RK maximally. We, therefore, deduced that the activation of RK for peptide phosphorylation in curve $(\nabla)$ of Figure 3 was promoted by the phosphorylated forms of Meta II/Meta III. The latter conclusion can also be drawn by a closer examination of the time-course curve in Figure 1, which shows that the bulk of Rho* phosphorylation occurred in the first $10 \mathrm{~min}$ following the initiation of photolysis. However, the peptide phosphorylation continued, almost linearly for $60 \mathrm{~min}$; during most of this time the Rho* was predominantly present in its phosphorylated form. Hence, the activation of RK, in this phase, must have occurred using the phosphorylated form of Rho*. Here, it should be pointed out that contrary to common belief, the Schiff base hydrolysis in ROS membranes, at $20^{\circ} \mathrm{C}$, is a very slow process. In the kinetic experiments described in [16] (e.g. Figures 2B and 2C), there was no evidence of Schiff base hydrolysis for at least $40 \mathrm{~min}$, which accounts for the fact that peptide phosphorylation, dependent on the activation of RK by photointermediates, was linear over the course of incubation. As stated above, the facile hydrolysis of the Schiff base in dodecyl maltoside may contribute to the fact that the peptide 


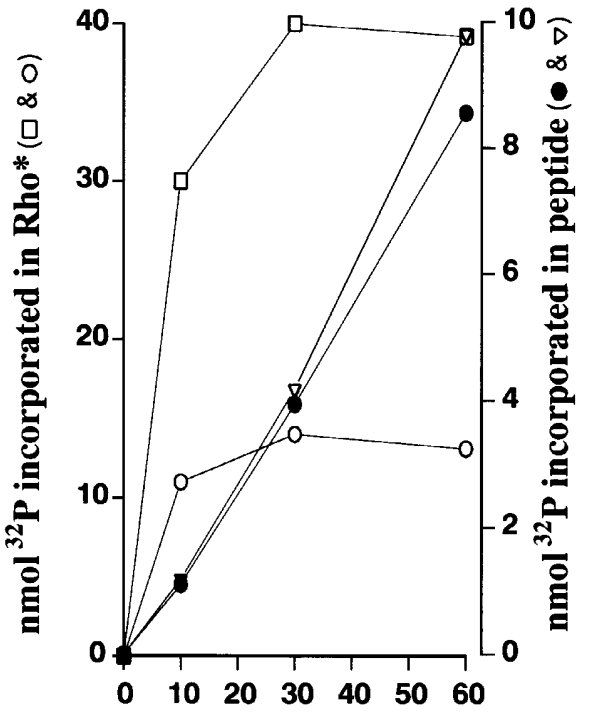

Time (mins)

Figure 3 Light-dependent phosphorylation of peptide substrate by RK in the presence of either isorhodopsin or phosphorylated isorhodopsin

Phosphorylation of peptide substrate in the incubation containing isorhodopsin $(\mathbf{O})$ or phosphorylated isorhodopsin $(\nabla)$. Phosphorylation of Rho* in the incubation containing isorhodopsin ( $\square$, at $60 \mathrm{~min}, 3.8 \mathrm{nmol}$ phosphate per nmol receptor protein was incorporated, as in a parallel incubation containing rhodopsin) or phosphorylated isorhodopsin ( $\bigcirc$, at $60 \mathrm{~min}$ a further incorporation of $1.2 \mathrm{nmol}$ phosphate per nmol receptor protein occurred). Dark controls were found to contain no more than $2 \%$ of the radioactivity incorporated in light. A typical result of this experiment is shown.

phosphorylation in this detergent decays with the passage of time (Figure 1).

\section{Opsin does not activate RK for peptide substrate phosphorylation}

Attention has already been drawn to the fact that the apoprotein opsin is not phosphorylated by RK [21-23]. Can opsin still act as an activator of RK? To address this question, in a pilot study, the phosphorylation reaction was performed in the presence of various concentrations of $\mathrm{NH}_{2} \mathrm{OH}$, in order to cleave the Schiff base linkage of Rho*. A concentration of $0.25 \mathrm{mM} \mathrm{NH}_{2} \mathrm{OH}$ was then selected for critical experiments and three parameters were measured: (a) the cleavage of Schiff base, (b) protein phosphorylation and (c) peptide phosphorylation. The Schiff base decay curve in Figure 4 shows that the phosphorylation of Rho*, in the presence of $0.25 \mathrm{mM} \mathrm{NH}_{2} \mathrm{OH}$, commenced at a rate similar to that in the control experiment but was gradually arrested with increasing cleavage of Schiff base. Once the latter reaction was nearly complete, at approx. $30 \mathrm{~min}$, no further Rho* phosphorylation was observed. The effect of cleavage is seen more clearly on the peptide phosphorylation because of its longer time course. Here, no significant ${ }^{32} \mathrm{P}$ incorporation occurred after $30 \mathrm{~min}$ when $86 \%$ of the Schiff base had been cleaved. The abolition of peptide phosphorylation, in the presence of $\mathrm{NH}_{2} \mathrm{OH}$ therefore must be due to the inability of opsin, or for that matter, phosphorylated opsin, to serve as an activator of RK. Two possible explanations for the inhibition of phosphorylation in the presence of $\mathrm{NH}_{2} \mathrm{OH}$ can be eliminated. First, it is not due to the inactivation of $\mathrm{RK}$ by $\mathrm{NH}_{2} \mathrm{OH}$, since the enzyme was found to be stable in the presence of the reagent for up to $1 \mathrm{~h}$ (results not shown). Secondly, the fact that the

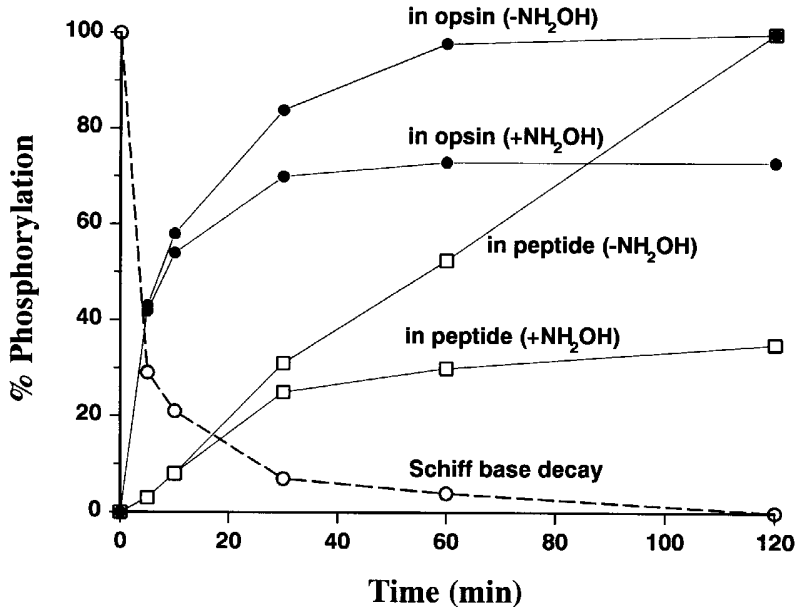

Figure 4 Profile of RK-catalysed phosphorylation at $20{ }^{\circ} \mathrm{C}$ in the presence of $\mathrm{NH}_{2} \mathrm{OH}$

The maximum incorporation of $43.4 \mathrm{nmol}$ of ${ }^{32} \mathrm{P}$ into Rho* and $34.3 \mathrm{nmol}$ of ${ }^{32} \mathrm{P}$ into the peptide substrate at $120 \mathrm{~min}$ in the absence of $\mathrm{NH}_{2} \mathrm{OH}$ is taken as $100 \%$. Phosphorylation of Rho* and the peptide substrate $(\square)$ as indicated above. A typical result of this experiment is shown. The decay of Schiff base was studied in a separate experiment performed similarly $(O$, $1 \mathrm{ml}$ volume; $12.5 \mathrm{nmol}$ rhodopsin), but not identically, to the above incubation as described in the Methods section.

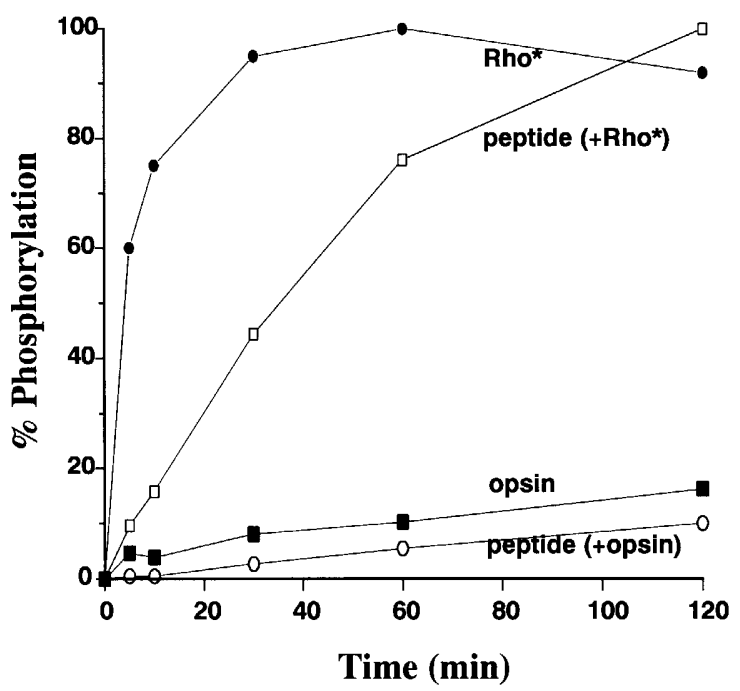

Figure 5 Profile of RK-catalysed phosphorylation at $20{ }^{\circ} \mathrm{C}$ in the presence of opsin

The maximum incorporation of $25.2 \mathrm{nmol}$ of ${ }^{32} \mathrm{P}$ into Rho* and $16.0 \mathrm{nmol}$ of ${ }^{32} \mathrm{P}$ into the peptide substrate at $120 \mathrm{~min}$ in the presence of urea-washed ROS is taken as $100 \%$. Phosphorylation of opsin $\left.(\mathbf{\square}), R^{*} o^{*}\right)$ and of the peptide substrate in the presence of either opsin $(O)$ or $\mathrm{Rho}^{*}(\square)$ are as indicated above. A typical result of this experiment is shown.

phosphorylation of $\mathrm{Rho}^{*}$, in the presence of $\mathrm{NH}_{2} \mathrm{OH}$, was maintained during the initial phase at a rate similar to that in the control experiment shows that the phosphoryl transfer process itself is not affected by $\mathrm{NH}_{2} \mathrm{OH}$.

Evidence to rule out further the involvement of $\mathrm{NH}_{2} \mathrm{OH}$ was provided by performing the phosphorylation of 11-mer Rho peptide in the presence of opsin. Figure 5 shows clearly that when compared with the parallel experiment containing urea-washed 
ROS, in the presence of authentic opsin, there is a dramatic reduction in the ability of RK to phosphorylate either the peptide substrate or opsin. In addition, it should be noted that the phosphate incorporation in the dark samples, in the presence of opsin, was to a similar level: $4 \%$ for the peptide and $7 \%$ for opsin.

\section{DISCUSSION}

The experiments described above establish beyond doubt that peptide phosphorylation is a property of an activated form of RK and is formed by the interaction of the enzyme with a range of derivatives of Rho*, which retains the Schiff base linkage between the all-trans-retinylidene moiety and opsin. In a previous study [9], we had considered two broad mechanisms for the activation process in which the activated form of RK was either present only in the Rho* RK complex [eqn (1)] or it could dissociate from the complex and exist as a freely diffusible species [eqn (2)]. Subsequently, preference was shown for the latter process [eqn (2)], because of the finding that RK when rapidly isolated from a suspension of Rho* and ATP was able to catalyse the phosphorylation of the dark-adapted form of rhodopsin [24], in a process known as 'high-gain' phosphorylation $[25,26]$. The latter conversion is considered to be a property of an activated form of RK.

Kinetic experiments reported in the literature [27] have shown that RK and Rho* form a tightly bound complex, the dissociation of which is progressively facilitated in the presence of ATP and, again, when these proteins become increasingly phosphorylated; RK by autophosphorylation and Rho* through conversion into multiphosphorylated-Rho*. A careful examination of the timecourse profile in Figure 1 (filled circle), or the equivalent curves of Figures 2-4, shows that the rate of light-dependent peptide phosphorylation is not significantly impaired after $15 \mathrm{~min}$ of the initiation of incubation when both RK and Rho* are expected to be present in optimally phosphorylated forms. Under this condition of a large increase in the off-rate of RK, from the $\mathrm{RK} \cdot \mathrm{Rho}$ * complex, the peptide phosphorylation is maintained at the initial rate. This may be cited as evidence, albeit weak, in favour of the proposition that the catalyst, i.e. activated RK, can exist as a diffusible entity, as shown by eqn (2). Such a view is, however, questioned by the experiments of Rim et al. [15].

In conclusion, the cumulative evidence available to date clearly shows that RK (GRK1) and other GRKs, in particular GRK2 and GRK3 [13,14], are present in an inactive resting state and are activated only after interaction with the activated form of their cognate receptors. However, the intimate mechanistic details of this activation process still remain elusive.

We thank Drs B. Broadbridge, Ram Sharma and Mrs M. Akhtar for their continued help throughout this project and Mr D. Williams (H. M. Funtley, Hants, U.K.) for the supply of retinas. A Wellcome Trust grant to Professor P. M. Schoolingin-Jordan was used to purchase a VG Quattro II mass spectrometer. We thank the Wellcome Trust for supporting our work in the field of vision. This work was also supported by grants from the Medical Research Council (U.K.) and the Ulverscroft Foundation.

\section{REFERENCES}

1 Palczewski, K. (1997) GTP-binding protein-coupled receptor kinases - two mechanistic models. Eur. J. Biochem. 248, 261-269
2 Kühn, H., Cook, J. H. and Dreyer, W. J. (1973) Phosphorylation of rhodopsin in bovine photoreceptor membranes. A dark reaction after illumination. Biochemistry $\mathbf{1 2}$ 2495-2502

3 Bownds, D., Dawes, J., Miller, J. and Stahlman, M. (1972) Phosphorylation of frog photoreceptor membranes induced by light. Nature, New Biol. 237, 125-127

4 Frank, R. N. and Buzney, S. M. (1975) Mechanism and specificity of rhodopsin phosphorylation. Biochemistry 14, 5110-5117

5 Matthews, R. G., Hubbard, R., Brown, P. K. and Wald, G. (1963) Tautomeric forms of metarhodopsin. J. Gen. Physiol. 47, 215-240

6 Kibelbek, J., Mitchell, D. C., Beach, J. M. and Litman, B. J. (1991) Functional equivalence of metarhodopsin II and the Gt-activating form of photolysed bovine rhodopsin. Biochemistry 30, 6761-6768

7 Kühn, H., Mommertz, O. and Hargrave, P. A. (1982) Light-dependent conformational change at rhodopsins cytoplasmic surface detected by increased susceptibility to proteolysis. Biochim. Biophys. Acta 679, 95-100

8 Fowles, C., Sharma, R. and Akhtar, M. (1988) Mechanistic studies on the phosphorylation of photoexcited rhodopsin. FEBS Lett. 238, 56-60

9 Brown, N. G., Fowles, C., Sharma, R. and Akhtar, M. (1992) Mechanistic studies on rhodopsin kinase. Light-dependent phosphorylation of C-terminal peptides of rhodopsin. Eur. J. Biochem. 208, 659-667

10 Palczewski, K., Buczylko, J., Kaplan, M. W., Polans, A. S. and Crabb, J. W. (1991) Mechanism of rhodopsin kinase activation. J. Biol. Chem. 266, 12949-12955

11 Pullen, N., Brown, N. G., Sharma, R. and Akhtar, M. (1993) Cooperativity during multiple phosphorylations catalysed by rhodopsin kinase: supporting evidence using synthetic phosphopeptides. Biochemistry 32, 3958-3964

12 Pullen, N. and Akhtar, M. (1994) Rhodopsin kinase: studies on the sequence of and the recognition motif for multiphosphorylations. Biochemistry 33, 14536-14542

13 Chen, C.-Y., Dion, S. B., Kim, C. M. and Benovic, J. L. (1993) Beta-adrenergic receptor kinase. Agonist-dependent receptor binding promotes kinase activation. J. Biol. Chem. 268, 7825-7831

14 Haga, K., Kameyama, K. and Haga, T. (1994) Synergistic activation of G proteincoupled receptor kinase by $\beta \gamma$ subunits and mastoparan or related peptides. J. Biol. Chem. 269, 12594-13599

15 Rim, J., Faurobert, E., Hurley, J. B. and Oprian, D. D. (1997) In vitro assay for transphosphorylation of rhodopsin by rhodopsin kinase. Biochemistry 36, 7064-7070

16 McCarthy, N. E. M. and Akhtar, M. (2000) Function of the farnesyl moiety in visual signalling. Biochem. J. 347, 163-171

17 Palczewski, K., Buczylko, J., Van Hooser, P., Carr, S. A., Huddleston, M. J. and Crabb, J. W. (1992) Identification of the autophosphorylation sites in rhodopsin kinase. J. Biol. Chem. 267, 18991-18998

18 DePont, J. J. H. H. M., Daemen, F. J. M. and Bonting, S. L. (1970) Biochemical aspects of the visual process. VII Equilibrium conditions in the formation of retinylidene imines. Arch. Biochem. Biophys. 140, 267-274

19 Applebury, M. L., Zuckermann, D. M., Lamola, A. A. and Jovin, T. M. (1974) Rhodopsin. Purification and recombination with phospholipids assayed by the metarhodopsin I to II transition. Biochemistry 13, 3448-3458

20 McCarthy, N. E. M. (1998) Mechanistic studies on rhodopsin kinase: a farnesylated protein, Ph.D. Thesis, University of Southampton, Southampton

21 Shichi, H. and Somers, R. L. (1978) Light-dependent phosphorylation of rhodopsin: purification and properties of rhodopsin kinase. J. Biol. Chem. 253, 7040-7046

22 Miller, J. A., Paulsen, R. and Bownds, M. D. (1977) Control of light-activated phosphorylation in frog photoreceptor membranes. Biochemistry 16, 2633-2639

23 McDowell, J. H. and Kühn, H. (1977) Light-induced phosphorylation of rhodopsin in cattle photoreceptor membranes: substrate activation and inactivation. Biochemistry 16. 4054-4060

24 Dean, K. R. and Akhtar, M. (1996) Novel mechanism for the activation of rhodopsin kinase: implications for other G protein-coupled receptor kinases (GRKs). Biochemistry 35, 6164-6172

25 Miller, J. A. and Paulsen, R. (1975) Phosphorylation and dephosphorylation of frog rod outer segment membranes as part of the visual process. J. Biol. Chem. 250. 4427-4432

26 Binder, B. M., Biernbaum, M. S. and Bownds, M. D. (1990) Light activation of one rhodopsin molecule causes the phosphorylation of hundreds of others. A reaction observed in electropermeabilised frog rod outer segments exposed to dim illumination. J. Biol. Chem. 265, 15333-15340

27 Pulvermüller, A., Palczewski, K. and Hofmann, K. P. (1993) Interaction between photoactivated rhodopsin and its kinase: stability and kinetics of complex formation. Biochemistry 32, 14082-14088

Received 1 August 2001/3 December 2001; accepted 22 January 2002 